\title{
Detection of tyrosine-phosphorylated proteins in hepatocellular carcinoma tissues using a combination of GST-Nck1-SH2 pull-down and two-dimensional electrophoresis
}

\author{
FANGHUA QIU ${ }^{1}$, DEHONG HUANG ${ }^{2}$, HONGGUANG XIAO ${ }^{3}$, FANGYING QIU $^{4}$, LIMING LU $^{1}$ and JING NIE $^{5}$ \\ ${ }^{1}$ Department of Clinical Laboratory, Guangzhou Hospital of Traditional Chinese Medicine; ${ }^{2}$ Department of Neurology, \\ Guangzhou Hospital of Traditional Chinese Medicine; ${ }^{3}$ Department of Clinical Laboratory, The First Affiliated Hospital of \\ Guangzhou Medical College; ${ }^{4}$ Department of Emergency, The Fourth Affiliated Hospital of Guangzhou Medical College; \\ ${ }^{5}$ Division of Nephrology, Nanfang Hospital, Southern Medical University, Research Institute of Nephrology \\ Guangdong Province, Key Laboratory for Organ Failure Research, Ministry of Education, Guangzhou, Guangdong, P.R. China
}

Received November 4, 2012; Accepted January 22, 2013

DOI: $10.3892 / \mathrm{mmr} .2013 .1324$

\begin{abstract}
Tyrosine-phosphorylated proteins govern a host of cell functions, such as growth, division, adhesion and motility. We previously identified a group of Nck Src homology 2 (SH2) domain-binding proteins by combining the GST-Nck1-SH2 pull-down method with two-dimensional electrophoresis (2-DE) in hepatocellular carcinoma (HCC) tissues. In the present study, different methods and conditions for key procedures of GST-Nck1-SH2 pull-down and 2-DE were investigated and optimized. High-resolution results were obtained using the following conditions: a total amount of $100 \mu \mathrm{l}$ GST-Nck1-SH2 fusion proteins/10 $\mathrm{mg}$ liver proteins to execute the pull-down procedure; $7 \mathrm{M}$ urea and $2 \mathrm{M}$ thiourea as lysis buffer; ultrafiltration depletion of interferential materials. Moreover, we performed a negative control experiment using GST-4T3 during the pull-down procedure, and further demonstrated that the proteins obtained using the aforementioned method interacted with Nck in a tyrosine phosphorylation-dependent manner. The optimized method offers a rapid, efficient alternative for the high-quantity screening of tyrosine-phosphorylated protein expression and solubility, which in turn facilitates future studies on tyrosine-phosphorylated proteins.
\end{abstract}

\section{Introduction}

Tyrosine-phosphorylated proteins govern a host of cell functions, such as growth, division, adhesion and motility (1). These proteins are critical regulators of signaling in the majority of

Correspondence to: Dr Dehong Huang, Department of Neurology, Guangzhou Hospital of Traditional Chinese Medicine, 16 Zhuji Road, Guangzhou, Guangdong 510130, P.R. China

E-mail: dh_huang@163.com

Key words: tyrosine phosphorylated proteins, GST-Nck1-Src homology 2, pull-down, two-dimensional electrophoresis, hepatocellular carcinoma tissues eukaryotic cellular pathways, and deregulated phosphorylation is involved in an array of diseases (2), including cancer (3).

Given their importance, a number of techniques have been used to study tyrosine-phosphorylated proteins, such as MS-based phosphoproteomic methods (4), redox-based probes (5), an Src homology 2 (SH2) profiling method based on far-western blot analysis (6), and the use of Grb2-SH2 domain binding proteins with SILAC (7).

The Nck adaptor protein consists of three SH3 domains followed by a C-terminal SH2 domain, and is capable of binding to numerous receptor tyrosine kinases via its $\mathrm{SH} 2$ domain (8). Dierck et al have developed an alternative phosphoproteomic method (termed SH2 profiling) to explore phosphotyrosine signaling in cancer cells (9), and have demonstrated that it is an ideal method to detect phosphotyrosine, due to its being highly sensitive and throughput.

However, these aforementioned studies were performed in cell lines. Therefore, the state of tyrosine-phosphorylated proteins in tumor tissues remains unknown. Our previous study successfully combined the GST-Nck1-SH2 pull-down with two-dimensional electrophoresis (2-DE) to detect tyrosine-phosphorylated proteins in liver tissues (10).

Although the combination of GST-Nck1-SH2 pull-down and 2-DE was able to detect tyrosine-phosphorylated proteins, it continues to involve numerous challenges. The greatest of those challenges was how to harvest samples from GST-Nck1-SH2 pull-down that are also compatible with downstream 2-DE. The efficiency of the GST-Nck1-SH2 pull-down method requires improvement in order that it yields sufficient tyrosine-phosphorylated proteins for downstream 2-DE. In addition, the samples obtained though the GST-Nck1-SH2 pull-down method include different types of interferential material, such as fragments of GST beads and iron, which are likely to affect the success of isoelectric focusing (IEF). Therefore, there is a requirement to deplete the interferential materials, while retaining the activity of the tyrosine-phosphorylated proteins. At present, to the best of our knowledge, few effective and detailed methods have been devised to obtain tyrosine-phosphorylated proteins from 
tissues by the use of the GST-Nck1-SH2 pull-down method. The present study set out to explore the effective techniques of GST-Nck1-SH2 pull-down, and to search for detailed methods regarding sample preparation for downstream 2-DE.

\section{Materials and methods}

Hepatocellular carcinoma (HCC) patient samples. HCC tissues were collected from $21 \mathrm{HCC}$ patients who underwent hepatectomy at the First Affiliated Hospital of Sun-Yat Sen University (Guangzhou, China). None of these patients had received preoperative chemotherapy or radiotherapy. Normal liver tissues were obtained from 8 patients diagnosed with liver hemangioma or cholelithiasis. Specimens were obtained with written informed consent from all patients. The study was conducted with prior approval from the Committees for Ethical Review of Research involving Human Subjects of the First Affiliated Hospital of Sun-Yat Sen University.

Plasmid constructs and transfection. The full-length dermcidin cDNA was amplified and cloned into the pReciever M06 expression vector (FulenGen Co., Ltd., Guangzhou, China). The GST-tagged SH2 domain of Nck was generated by PCR amplification of the human Nck template, and then ligated into the pGEX-4T-3 expression vector.

GST fusion protein purification. Escherichia coli (BL21) was transformed with pGEX-4T-3 or pGEXNck-SH2 incubated with $0.2 \mathrm{mM}$ isopropyl- $\beta$-D-1-thiogalactopyranoside (IPTG) for $4 \mathrm{~h}$. The GST fusion proteins were purified from bacterial lysates with GSH-Sepharose 4B beads, according to the manufacturer's instructions (Amersham Biosciences Corp., Picataway, NJ, USA). Tissue/cell lysates were prepared and spun at $15,000 \mathrm{x} \mathrm{g}$ for $15 \mathrm{~min}$.

GST pull-down. The liver proteins were incubated with GST-Nck1-SH2-conjugated sepharose beads for $2 \mathrm{~h}$ at $4^{\circ} \mathrm{C}$. Following incubation, the supernatant was removed and the beads were washed with a Tris-sucrose solution $(10 \mathrm{mM}$ Tris-HCl; $150 \mathrm{mM} \mathrm{NaCl} ; 1 \%$ Triton X-100, pH 7.5) to remove any non-specific or non-covalently bound proteins. The fusion proteins were eluted with $2 \mathrm{ml} 2-\mathrm{D}$ lysis buffer $(10 \mathrm{mM}$ reduced glutathione in $50 \mathrm{mM}$ Tris- $\mathrm{HCl}, \mathrm{pH} 8.0$ ) and desalted by ultrafiltration.

2-D clean-up. 2-D clean-up was performed according to the manufacturer' instructions (Amersham Biosciences Corp.).

Ultrafiltration. Samples were loaded into centrifuge tubes with a $10-\mathrm{kDa}$ membrane, in order to concentrate the proteins and remove small interference molecules. Samples were centrifuged at $5,000 \mathrm{xg}$, at $4^{\circ} \mathrm{C}$ for $1 \mathrm{~h}$.

2-DE and image analysis. Protein samples $(250 \mu \mathrm{g})$ were diluted to $450 \mu \mathrm{l}$ with a rehydration solution (7 M urea, $4 \%$ CHAPS, 0.5\% IPG ampholyte, $65 \mathrm{mM}$ DTE, $2 \mathrm{M}$ thiourea, and $0.0002 \%$ bromophenol blue), and then loaded onto IPG gel strips (pH 3.0-10.0 linear, $24 \mathrm{~cm}$ long; Amersham Biosciences Corp.). The first dimensional separation was performed using the IPGphor system (Amersham Biosciences Corp.) at $18^{\circ} \mathrm{C}$

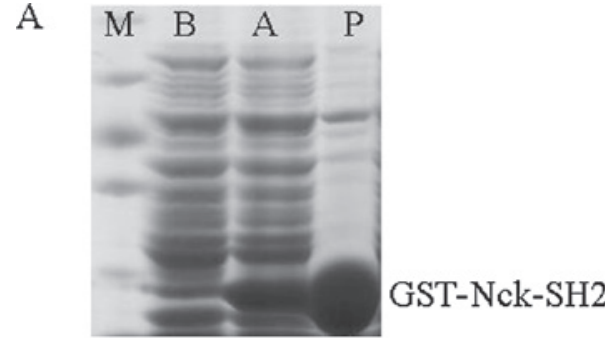

B

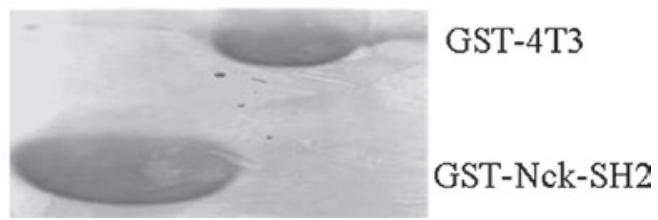

Figure 1. Induction and purification of GST-Nck1-Src homology 2 (SH2). Escherichia coli (BL21) was transformed with pGEX-4T-3 or pGEXNck-SH2, and incubated with $0.2 \mathrm{mM}$ IPTG for $4 \mathrm{~h}$. The GST fusion proteins were purified from bacterial lysates with GSH-Sepharose 4B beads, then $15 \mathrm{ml}$ was loaded on each lane of the gel and stained with Coomassie blue. (A) Induction and purification of GST-Nck1-SH2. M, marker; B, before IPTG induction; A, after IPTG induciton; P, GST-Nck-SH2 fusion proteins. (B) Comparison of GST-Nck1-SH2 and GST-4T3.

with $8,000 \mathrm{~V}$, for a total of $90 \mathrm{k}$ VHS. Following IEF, the IPG strips were subjected to reduction with $2 \%$ DTE in equilibration solution $(50 \mathrm{mM}$ Tris- $\mathrm{HCl}, \mathrm{pH} 8.8 ; 6 \mathrm{M}$ urea; $2 \%$ SDS; $30 \%$ glycerol), followed by alkylation with $2.5 \%$ iodoacetamide in the same buffer. The gels were stained with Silver Staining kit (Amersham Biosciences Corp.) according to the manufacturer's instructions. The developed gels were scanned as 2-DE images using an image scanner, and then analyzed using ImageMaster software (Amersham Biosciences Corp.).

In-gel digestion and protein identification. 2-DE gels of interest were washed in water/acetonitrile (ACN; 1:1) and then dehydrated in ACN. The gel pieces were air-dried and rehydrated in $20 \mu \mathrm{l}$ of $10 \mathrm{mM}$ DTT and $0.1 \mathrm{M} \mathrm{NH}_{4} \mathrm{HCO}_{3}$. Reduction of disulfide bonds was performed at $56^{\circ} \mathrm{C}$ for $45 \mathrm{~min}$. The supernatant was discarded and cysteine residues were modified to S-carboxyamidomethylcysteine in $55 \mathrm{mM}$ iodoacetamide and $0.1 \mathrm{M} \mathrm{NH}_{4} \mathrm{HCO}_{3}$. After washing with $0.1 \mathrm{M} \mathrm{NH}_{4} \mathrm{HCO}_{3} / \mathrm{ACN}$ (1:1) for $15 \mathrm{~min}$, followed by ACN, the gel pieces were air-dried, rehydrated in chilled $50 \mathrm{mM} \mathrm{NH}_{4} \mathrm{HCO}_{3}$ and $12.5 \mathrm{ng} / \mu \mathrm{l}$ trypsin, and then incubated at $37^{\circ} \mathrm{C}$ overnight. The supernatant was collected and peptides were extracted twice from the gel with $50 \mathrm{mM} \mathrm{NH} \mathrm{HCO}_{3} / \mathrm{ACN}$ (1:1) followed by $5 \%$ formic acid/ ACN (1:1). The combined extracts were evaporated to dryness in a vacuum centrifuge. Prior to mass spectrometric analysis, peptides were re-dissolved in $10 \mu \mathrm{l}$ of $0.1 \%$ formic acid. Online peptide separation was performed after trapping each sample on a $180 \mu \mathrm{m}$ x 20 mm Symmetry ${ }^{\circledR}$ C18 Nano Acquity ${ }^{\mathrm{TM}}$ UPLC $^{\mathrm{TM}}$ column with $1 \%$ ACN and $0.1 \%$ formic acid at a $15 \mathrm{ml} / \mathrm{min}$ flow rate; following separation on a $75 \mu \mathrm{m}$ x $250 \mathrm{~mm}$ BEH130 column (Nano Aquity ${ }^{\mathrm{TM}}$ UPLC $^{\mathrm{TM}}$ ) with a 50 -min gradient from 5 to $95 \% \mathrm{ACN}$ and $0.1 \%$ formic acid, at a flow rate of $300 \mathrm{nl} / \mathrm{min}$. A tapered fused silica was used as an emitter. Mass analyses were performed with a quadrupole time-of-flight mass spectrometer (QTOF, Waters Corp., Milford, MA, USA). The 
Table I. Approximate yield using different methods.

\begin{tabular}{lcccc}
\hline Method & $\begin{array}{c}\text { GST-Nck1-SH2 fusion protein } \\
(\mu \mathrm{l})\end{array}$ & $\begin{array}{c}\text { Liver protein } \\
(\mathrm{mg})\end{array}$ & $\begin{array}{c}\text { Yield } \\
(\mu \mathrm{g})\end{array}$ & Protein spots \\
\hline A & 100 & 1 & $100 \pm 5$ & $50 \pm 5$ \\
B & 200 & 1 & $123 \pm 6$ & $70 \pm 15$ \\
C & 100 & 10 & $1202 \pm 28$ & $200 \pm 38$ \\
D & 100 & 20 & $1301+32$ & $238 \pm 43$ \\
\hline
\end{tabular}

SH2, Src homology 2 .

A

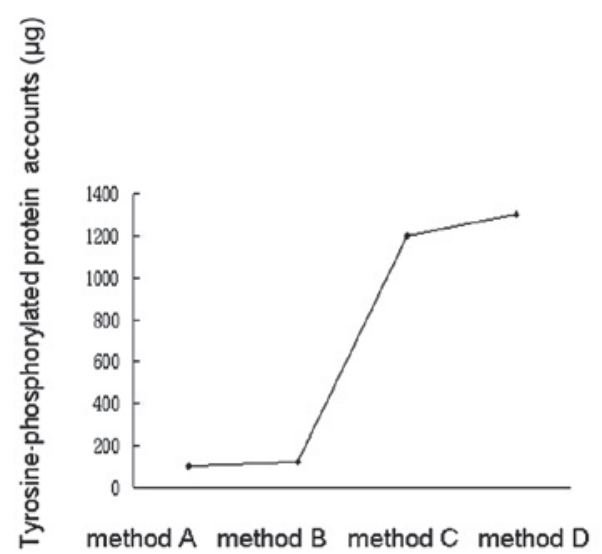

B
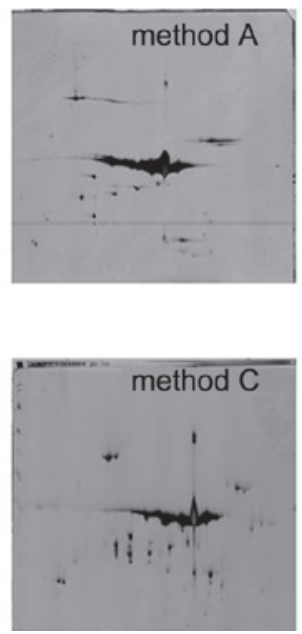
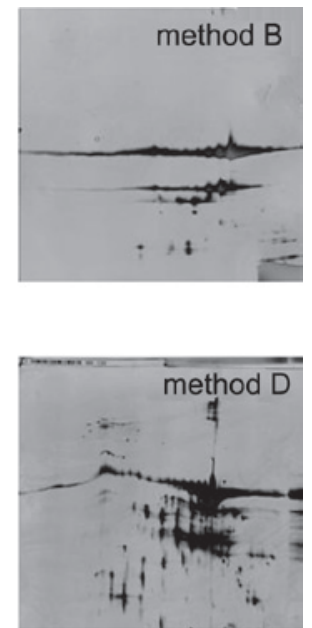

Figure 2. Different strategies employed to yield tyrosine-phosphorylated proteins. (A) Comparison of different strategies to yield tyrosine-phosphorylated proteins. Protein yields obtained by methods A, B, C and D were $100 \pm 5,123 \pm 6,1202 \pm 28$ and $1301 \pm 32 \mu \mathrm{g}$, respectively. (B) Two-dimensional electrophoresis (2-DE) was used to confirm the effect of the above strategies. Protein spots $(50 \pm 5,70 \pm 15,200 \pm 38$ and $238 \pm 43)$ were detected on the 2 -DE gels of methods A, B, C and D, respectively.

mass spectrometer was operated in a data-dependent mode to automatically switch between MS and MS/MS acquisition. Survey MS spectra (m/z 400-1800) were acquired in the QTOF, and the four most intense ions in each survey scan were fragmented and analyzed. Proteins were identified by automated database searching (Spectrum Mill; Agilent Technologies UK Ltd., Wokingham, UK) and MASCOT (Matrix Science, London, UK), of all MS and MS/MS spectra using the IPI Human, Swiss-Prot and NCBinr databases. Raw data files were converted to .pkl files by the Protein Lynx Global Server (PLGS; Waters Corp.). Search parameters were set as follows: MS accuracy, 0.15 Da; MS/MS accuracy, 0.15 Da; two missed cleavage allowed. Variable carbamidomethyl modification of cystine and variable oxidation of methionine, and all entries of the databases were searched.

\section{Results}

Induction and purification of GST-Nck1-SH2. The first key step of our study was to induce and purify the GST-Nck1-SH2 fusion proteins. As shown in Fig. 1A, following induction with isopropyl- $\beta$-D-1-thiogalactopyranoside (IPTG), the level of GST-Nck1-SH2 fusion proteins notably increased. To confirm the specificity of tyrosine-phosphorylated proteins which are the 'prey' proteins that are pulled down by by GST-Nck1-SH2, we performed negative control experiments with GST-4T3, under the same conditions. The comparison between GST-4T-3 and GST-Nck1-SH2 is shown in Fig. 1B. These results demonstrated that the induction and purification of GST-Nck1-SH2 fusion proteins were successful.

Comparison of different strategies for capturing tyrosine-phosphorylated proteins by the GST-Nck1-SH2 pull-down method. In order to yield sufficient tyrosine-phosphorylated proteins by GST-Nck1-SH2 pull-down, we explored different pull-down strategies to detect the 'prey' proteins in liver tissues (Table I). According to the general guidelines of GST pull-down in cells, we employed $100 \mu$ l GST-Nck1-SH2 fusion proteins to pull down the 'prey' tyrosine-phosphorylated proteins among $1 \mathrm{mg}$ liver proteins in method A. However, in method B, we optimized the quantity of GST-Nck1-SH2 fusion protein to $200 \mu \mathrm{l}$; while in methods C and D, 10 and $20 \mathrm{mg}$ of liver protein was added, respectively. Protein yields pulled down by methods A, B, C and D were $100 \pm 5,123 \pm 6$, $1202 \pm 28$ and $1301 \pm 32 \mu \mathrm{g}$, respectively. As demonstrated in Fig. 2A, method C (100 $\mu \mathrm{l}$ fusion protein/10 mg liver protein) and method D (100 $\mu \mathrm{l}$ fusion protein/20 mg liver protein) were able to markedly increase the protein accounts, while methods A and B yielded insufficient quantities of protein for downstream tests. 


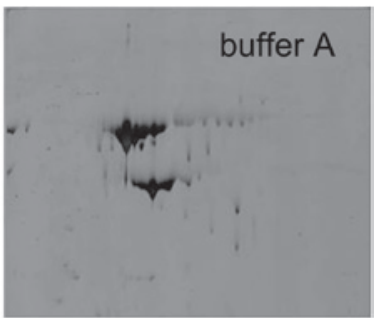

B

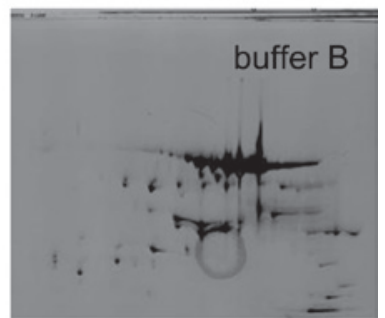

Figure 3. Comparison of different types of lysis buffer for dissolving proteins. The sample result from GST-Nck1-Src homology 2 (SH2) pull-down was dissolved by lysis buffer A (8 M urea, 4\% CHAPS, $50 \mathrm{mM}$ DTT) and $\mathrm{B}$ (7 M urea and $2 \mathrm{M}$ thiourea, 4\% CHAPS, $50 \mathrm{mM}$ DTT). Subsequently, $100 \mu \mathrm{g}$ protein was separated over a pH range of 3.0-10.0 (24-cm strips) and $12.5 \%$ SDS-polyacrylamide gel. The gel was visualized by silver staining (A) Two-dimensional (2-D) gel result from lysis buffer A; $89 \pm 40$ protein spots. (B) 2-D gel result from lysis buffer B; $200 \pm 38$ protein spots.

We set out to further investigate the effect of the previous strategies; samples pulled down by the aforementioned methods were loaded to 2-DE gels. As shown in Fig. 2B, protein spots of method A, B, C and D were $50 \pm 5,70 \pm 15$, $200 \pm 38$ and $238 \pm 43$, respectively. The $2-\mathrm{D}$ gel results for methods $\mathrm{C}$ and $\mathrm{D}$ contained more protein spots than methods $\mathrm{A}$ and $\mathrm{B}$; however, the 2-D gel for method D exhibited horizontal streaks and blurry protein spots. Additionally, the 2-D gel for method B exhibited only large GST beads. Overall, method $\mathrm{C}$ was selected for further study.

Comparison of different types of lysis buffer for dissolving proteins. Commonly, there are two types of lysis buffer for dissolving proteins. The standard cocktail contains $8 \mathrm{M}$ urea (chaotropic), 4\% CHAPS (detergent) and $50 \mathrm{mM}$ DTT (lysis buffer $\mathrm{A}$ ); while the other buffer contains $7 \mathrm{M}$ urea and $2 \mathrm{M}$ thiourea (lysis buffer B) in place of $8 \mathrm{M}$ urea. The latter buffer type is capable of increasing the solubility of certain proteins and producing more spots, which is consistent with our results: Buffer A, $89 \pm 40$ protein spots; buffer B, $200 \pm 38$ protein spots (Fig. 3A and B). Overall, buffer B was used for further sample preparation.

Comparison of different methods for depleting the interferential materials. The resulting samples from GST-Nck1-SH2 pull-down include different types of material that affect the success of IEF. Therefore, we selected three types of typical methods for deleting the interferential materials to explore. These methods included a mini dialysis kit ( $8 \mathrm{kDa}$, Amersham Biosciences Corp.), a 2-D clean-up kit (Amersham Biosciences Corp.) and ultrafiltration (10 kDa, Millipore, Biosciences, NJ, USA). To delete the interferential materials, the samples must be loaded onto 2-DE gels. As shown in Fig. 4A, the 2-D gel for the mini dialysis kit was of poor quality, with horizontal
A

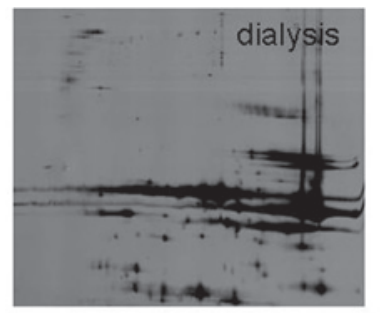

B

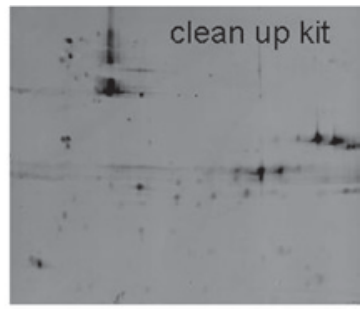

C

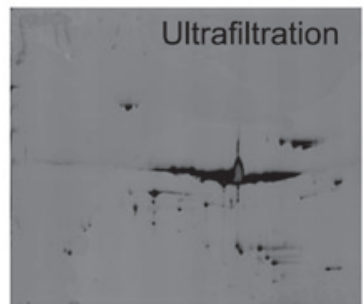

Figure 4. Comparison of depletion efficiency for interferential materials by two-dimensional electrophoresis (2-DE). A mini dialysis kit, a 2-D clean-up kit and ultrafiltration were employed to deplete the interferential materials. Subsequently, $100 \mu \mathrm{g}$ protein, following deletion, were loaded onto 2-DE gels. For each gel, $100 \mu \mathrm{g}$ protein was separated over a pH range of 3.0-10.0 (24-cm strips) and $12.5 \%$ SDS-polyacrylamide gel. The gel was stained with silver. (A) 2-D gel for the mini dialysis kit depletion shows horizontal streaks and blurry protein spots. (B) 2-D gel for the 2-D clean-up kit depletion has a limited number of remaining protein spots. (C) 2-D gel result from ultrafiltration depletion has $210 \pm 18$ protein spots.

streaks and blurry protein spots, suggesting that IEF had failed due to an incomplete removal of salts and GST fragments by the kit. However, the 2-D clean-up kit removed the fragments of the GST beads effectively, while also cleaning the majority of the tyrosine-phosphorylated proteins (Fig. 4B); only a few protein spots remained following depletion. As shown in Fig. 4C, $210 \pm 18$ spots were detected after ultrafiltration depletion. Overall, ultrafiltration was chosen to be further tested.

Negative control of the GST-Nck1-SH2 pull-down procedure. An appropriate control experiment should be conducted during the GST-Nck1-SH2 pull-down procedure. In the present study, we performed a negative control experiment by the use of GST-4T3. The proteins pulled down by GST-Nck1-SH2 fusion or GST-4T3 underwent removal of the interferential materials by ultrafiltration, and were then loaded onto 2-DE gels under the same conditions. As shown in Fig. 5, the 2-D gel for GST-Nck1-SH2 separated $200 \pm 38$ protein spots while that of GST-4T3 possessed GST fragments and few protein spots.

Proteins obtained using our method interacted with Nck in a tyrosine phosphorylation-dependent manner. To demonstrate whether the proteins that were pulled down by our method interacted with Nck in a tyrosine phosphorylation-dependent manner, we firstly identified two proteins by MALDI-TOF/ TOF MS [Fig. 5B; lane 1, dermcidin (DCD); lane 2, engulfment and cell motility proteins (Elmo1)]. These results were published in our previous study (10).

Co-immunoprecipitation (co-IP) experiments were used to examine the correlation between endogenous Elmo1/DCD and Nck in SK-HEP-1 cells. As demonstrated in Fig. 6A, DCD was detected by anti-DCD antibody in the anti-Nck immunoprecipitate, but not in the precipitate obtained by IgG. In Fig. 6B, 


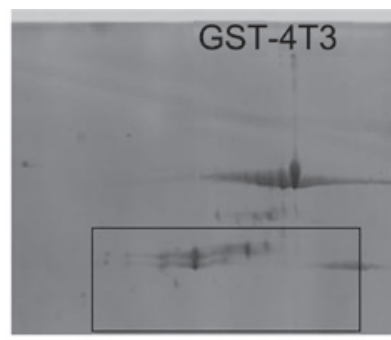

B

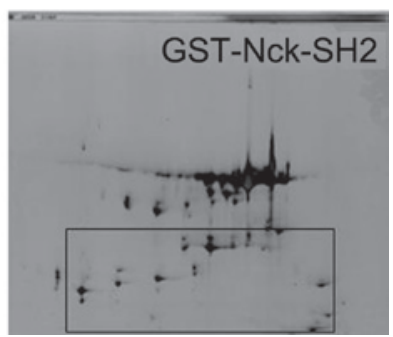

Figure 5. Two-dimensional (2-D) gel of GST-4T-3 and GST-NCK-Src homology 2 (SH2). For each gel, $100 \mu$ g protein were separated over a $\mathrm{pH}$ range of 3.0-10.0 (24-cm strips) and 12.5\% SDS-polyacrylamide gel. The gel was visualized by silver staining. 2-D gel of (A) GST-4T3 control and (B) GST-Nck1-SH2. The rectangle emphasizes the different protein patterns in the two groups; the 2-D gel of GST-4T3 has numerous GST fragments and few protein spots while that of GST-Nck-SH2 has $200 \pm 38$ protein spots.
A

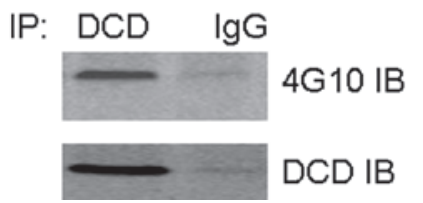

B

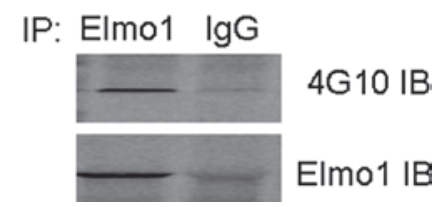

Figure 6. Coimmunoprecipitation was used to confirm the interaction of dermcidin (DCD) and Nck1, engulfment and cell motility proteins (Elmo1) and Nck1, in a tyrosine phosphorylation-dependent manner. SK-HEP-1 cell lysates were immunoprecipitated with an anti-Nck1 antibody or IgG as a control, followed by anti-DCD or anti-Nck immunoblot. (A) DCD was detected by anti-DCD antibody in the anti-Nck1 immunoprecipitate, but not in the precipitate obtained by IgG. (B) Elmo1 was detected by anti-Elmol antibody in the anti-Nck immunoprecipitate, but not in the precipitate obtained by IgG.

Elmo1 was detected by anti-Elmol antibody in the anti-Nck immunoprecipitate, but not in the precipitate obtained by IgG. Subsequent tests used to demonstrate that the proteins interact with Nck in a tyrosine phosphorylation-dependent manner have been published in our previous study (10).

\section{Discussion}

Given the importance of signaling mediated by tyrosine-phosphorylated proteins, there is significant interest in strategies to define or profile the global state of tyrosine phosphorylation in the cell (11). A limited number of studies have focused on tyrosine-phosphorylated proteins in tumor tissues thus far, although these regulate many important cancer-related activities, including cell proliferation, survival, invasion/metastasis and angiogenesis (12). Therefore, profiling the global state of tyrosine-phosphorylated proteins in a tumor is likely to provide a wealth of information that may be used to classify tumors for prognosis and prediction (13). To detect the state of tyrosine-phosphorylated proteins in tumor tissues, we selected liver tissue from $\mathrm{HCC}$ patients for further study. HCC is one of the most common and aggressive human malignancies (14), and is also regulated by tyrosine-phosphorylated proteins.

Machida et al demonstrated that $\mathrm{SH} 2$ binding methods may serve as a valuable complement in large-scale proteomic analyses (6). GST pull-down is an important tool for the validation of suspected protein-protein interactions, or for identifying novel protein interactions. 2-DE is one of the most commonly used methods in proteome analysis and classified tumors (15). Given this background, we employed GST-Nck1-SH2 pull-down to detect tyrosine-phosphorylated proteins in liver tissues, and then combined this with 2-DE to separate the proteins.

Although 2-DE is a powerful way to separate proteins for proteomics analysis, it presents a challenge for sample preparation (16). Based on the present study, the major barriers include the quantity of protein, depletion of interferential materials and certainty that the proteins obtained by GST-Nck1-SH2 pull-down are tyrosine-phosphorylated proteins.

Protein amounts. Yielding sufficient proteins is the initial step required for 2-DE, as the protein concentration of the loading sample for silver-stained 2-DE gels should not be $<0.5 \mu \mathrm{g} /$ $\mu l$ (17). To capture sufficient tyrosine-phosphorylated proteins by GST-Nck1-SH2 pull-down, we explored four different methods. The first method involved following the guidelines for GST pull-down in cells. However, our results demonstrated that this method was not suitable for tissue samples as it only yielded a limited number of tyrosine-phosphorylated proteins. Subsequently, we optimized the quantity of GST-Nck1-SH2 particles or liver proteins in methods B, C and D, respectively. The quantity of tyrosine-phosphorylated protein in methods $\mathrm{C}$ and D markedly increased. We further confirmed the effect of the four different strategies by 2-DE. Overall, our results demonstrated that protein accounts obtained by GST pull-down were dependent on the ratio of GST-Nck1-SH2 fusion proteins to liver proteins. Only with an appropriate ratio (method C) are ideal accounts obtained, employing a greater quantity of liver proteins (method D) or fusion proteins (method B) did not lead to a greater amount of tyrosine-phosphorylated proteins being obtained. By contrast, using a large excess of particles or liver proteins would result in non-specific interactions between the proteins and particles.

Protein denaturization is another key step of 2-DE that is often achieved by the addition of chaotropic agents, such as urea and thiourea. Variations in the components and concentration of chaotropic agents markedly affect protein amounts and patterns. Thiourea is known to be able to increase the solubility of certain proteins and produce more protein spots, which is consistent with the present results.

Depletion efficiency and compatibility for downstream 2-DE. 2-DE is often limited by the presence of non-protein impurities in the samples. Excess salts originate from sample preparation and may render the solution too conductive for effective IEF. The samples resulting from GST-Nck1-SH2 pull-down included iron in the wash buffer and GST particle fragments, all of which negatively impact IEF. Therefore, depletion of such interferential material is an important step to insure successful IEF. To ensure 
samples pulled down by GST-Nck1-SH2 may be used for downstream proteomics studies, we selected three common methods, acetone, a 2-D clean-up kit and ultrafiltration, to deplete the aforementioned materials, and then loaded the samples onto 2-DE gels.

To evaluate the depletion method, the depletion efficiency and the protein yield post-depletion were assessed. Dialysis is a simple and straightforward technique to de-salting with a dialysis membrane. The capped tube with the sample is inverted in a stirred beaker containing the solution against salts and molecules smaller than the molecular weight cut-off of the dialysis membrane exchange. However, our results demonstrated that dialysis could not be used for present study. A possible reason for this is that the samples resulting from GST-Nck1-SH2 pull-down included the majority of the GST bead fragments, which would block the dialysis membrane and result in failure of dialysis.

The 2-D clean-up kit is the classical depletion kit and it may be used to prepare proteins from sources that are diluted, and that contain high levels of salt and other interfering substances. However, our study demonstrated that this method was not suitable for tyrosine-phosphorylated proteins as a limited number of protein spots remained following depletion. We suggest that the reason for this finding is that the 2-D clean-up kit applies chemicals to the precipitant proteins, and the tyrosine-phosphorylated proteins require a tender method in order to retain their activity, thus any type of chemical modification would result in a loss of activity.

Ultrafiltration is a mild method for desalting and removal of materials of low molecular weight by centrifugalization that does not require a phase change. Thus, it is able to maintain the activity of tyrosine-phosphorylated proteins effectively. Overall, we suggest that ultrafiltration is a more appropriate method compared with the other methods.

Confirmation that the proteins obtained by GST-Nck1-SH2 pull-down are tyrosine-phosphorylated proteins. The disadvantage of GST-4T3 pull-down is the interferential interaction by any non-specific or non-covalently bound proteins. To eliminate false positives resulting from non-specific interactions, we performed a negative control experiment using GST-4T3 during the pull-down procedure, and subsequently loaded the samples pulled down by both GST-4T3 and GST-Nck1-SH2 onto 2-DE gels. Our results demonstrated that the 2-D gel for GST-Nck1-SH2 harvested more protein spots than that of GST-4T3.

We further identified DCD and Elmol by MALDI-TOF/ TOF MS on the 2-D gel and demonstrated that the proteins pulled down by our method, which interacted with Nck in a tyrosine phosphorylation-dependent manner, were either DCD or Elmo1. As the SH2 domain is a small, modular protein domain that binds specifically to tyrosine-phosphorylated peptide ligands, we suggest that the present strategy is effective for identifying novel SH2 domains associated with phosphorylated proteins in tumor tissues.

In summary, we have optimized the GST-Nck1-SH2 pull-down procedure to obtain tyrosine-phosphorylated proteins in tumor tissues, and the sample preparation for downstream 2-DE. Moreover, the successful identification of protein spots by MALDI-TOF/TOF MS and the proteins pulled down by our method, which interacted with Nck in a tyrosine phosphorylation-dependent manner, demonstrated that GST-Nck1-SH2 pull-down combined with 2-DE is an effective molecular diagnostic approach to identifying novel SH2 domains associated with phosphorylated proteins in tumor tissue, thus facilitating future research.

\section{Acknowledgements}

This study was supported by a grant (No. 81070554) from the National Science Foundation of China.

\section{References}

1. Barr AJ: Protein tyrosine phosphatases as drug targets: strategies and challenges of inhibitor development. Future Med Chem 2: 1563-1576, 2010.

2. Soderblom EJ, Philipp M, Thompson JW, Caron MG and Moseley MA: Quantitative label-free phosphoproteomics strategy for multifaceted experimental designs. Anal Chem 83: 3758-3764, 2011

3. Morishita A, Gong J, Nomura T, Yoshida H, Izuishi K, Suzuki Y, Kushida Y, Haba R, D'Armiento J and Masaki T: The use of protein array to identify targetable receptor tyrosine kinases for treatment of human colon cancer. Int J Oncol 37: 829-835, 2010.

4. Alcolea MP, Kleiner O and Cutillas PR: Increased confidence in large-scale phosphoproteomics data by complementary mass spectrometric techniques and matching of phosphopeptide data sets. J Proteome Res 8: 3808-3815, 2009.

5. Kuban-Jankowska A, Gorska M, Debicki A, Popowska U, Knap N and Wozniak M: Protein tyrosine phosphatases - endogenous markers of oxidative stress. Postepy Biochem 56: 269-273, 2010 (In Polish).

6. Machida K, Mayer BJ and Nollau P: Profiling the global tyrosine phosphorylation state. Mol Cell Proteomics 2: 215-233, 2003.

7. Blagoev B, Kratchmarova I, Ong SE, Nielsen M, Foster LJ and Mann M: A proteomics strategy to elucidate functional protein-protein interactions applied to EGF signaling. Nat Biotechnol 21: 315-318, 2003.

8. Bladt F, Aippersbach E, Gelkop S, Strasser GA, Nash P, Tafuri A, Gertler FB and Pawson T: The murine Nck SH2/SH3 adaptors are important for the development of mesoderm-derived embryonic structures and for regulating the cellular actin network. Mol Cell Biol 23: 4586-4597, 2003.

9. Dierck K, Machida K, Voigt A, Thimm J,Horstmann M,Fiedler W, Mayer BJ and Nollau P: Quantitative multiplexed profiling of cellular signaling networks using phosphotyrosine-specific DNA-tagged SH2 domains. Nat Methods 3: 737-744, 2006.

10. Shen SL, Qiu FH, Dayarathna TK, Wu J, Kuang M, Li SS, Peng BG and Nie J: Identification of Dermcidin as a novel binding protein of Nck1 and characterization of its role in promoting cell migration. Biochim Biophys Acta 1812: 703-710, 2011.

11. Machida K, Thompson CM, Dierck K, et al: High-throughput phosphotyrosine profiling using SH2 domains. Mol Cell 26: 899-915, 2007.

12. Blume-Jensen $P$ and Hunter T: Oncogenic kinase signalling. Nature 411: 355-365, 2001.

13. Machida K, Eschrich S, Li J, Bai Y, Koomen J, Mayer BJ and Haura EB: Characterizing tyrosine phosphorylation signaling in lung cancer using SH2 profiling. PLoS One 5: e13470, 2010.

14. Kudo $M$ and Okanoue T; Japan Society of Hepatology: Management of hepatocellular carcinoma in Japan: consensus-based clinical practice manual proposed by the Japan Society of Hepatology. Oncology 72 (Suppl 1): 2-15, 2007.

15. Kikuchi T and Carbone DP: Proteomics analysis in lung cancer: challenges and opportunities. Respirology 12: 22-28, 2007.

16. Wu Y, Zhou J, Zhang X, Zheng X, Jiang X, Shi L, Yin W and Wang J: Optimized sample preparation for two-dimensional gel electrophoresis of soluble proteins from chicken bursa of Fabricius. Proteome Sci 7: 38, 2009.

17. Liu B, Qiu FH, Voss C, Xu Y, Zhao MZ, Wu YX, Nie J and Wang ZL: Evaluation of three high abundance protein depletion kits for umbilical cord serum proteomics. Proteome Sci 9: 24, 2011. 